\title{
Correction to: Ecofriendly remediation technologies for wastewater contaminated with heavy metals with special focus on using water hyacinth and black tea wastes: a review
}

\author{
Heba Elbasiouny • Marwa Darweesh • Hala Elbltagy • Fatma G. Abo-alhamd • Ahlam A. Amer • \\ Mariam A. Elsegaiy • Israa A. Khattab • Esraa A. Elsharawy • Fathy Elbehiry • Hassan El-Ramady • \\ Eric C. Brevik
}

Published online: 31 July 2021

(C) Springer Nature Switzerland AG 2021

\section{Correction to: Environ Monit Assess (2021) 193: 449 https://doi.org/10.1007/s10661-021-09236-2}

The original version of this article unfortunately contained a mistake in the author names.

The second, third and ninth author names Marwa Darwesh, Hala Elbeltagy, Fathy Ebehiry should be corrected as follows Marwa Darweesh, Hala Elbltagy, and Fathy Elbehiry.

The corrected author names are shown in the author group and affiliation section.

The original article can be found online at https://doi.org/ 10.1007/s10661-021-09236-2.

H. Elbasiouny · M. Darweesh · H. Elbltagy ·

F. G. Abo-alhamd · A. A. Amer · M. A. Elsegaiy •

I. A. Khattab - E. A. Elsharawy

Department of Environmental and Biological Sciences, Al-

Azhar University, Home Economics Faculty, Tanta 31732,

Egypt

F. Elbehiry

Central Laboratory of Environmental Studies,

Kafrelsheikh University, Kafr El-Sheikh 33516, Egypt

H. El-Ramady

Soil and Water Dept, Faculty of Agriculture, Kafrelsheikh

University, Kafr El-Sheikh 33516, Egypt

e-mail: hassan.elramady@agr.kfs.edu.eg

E. C. Brevik $(\square)$

College of Agricultural, Life, and Physical Sciences,

Southern Illinois University, Carbondale, IL 62901, USA

e-mail: calpsdean@siu.edu
Publisher's Note Springer Nature remains neutral with regard to jurisdictional claims in published maps and institutional affiliations. 